\title{
Sexual isolation and cuticular hydrocarbons in Drosophila elegans
}

\author{
KAORI ISHII†, YOSHIYUKI HIRAI†, CHIHIRO KATAGIRI $\$$ \& MASAHITO T. KIMURA $\dagger^{*}$ \\ $\uparrow$ Graduate School of Environmental Earth Science, Hokkaido University, Sapporo, Hokkaido 060-0810, and \\ $\$$ Biochemistry Laboratory, Institute of Low Temperature Science, Hokkaido University, Sapporo, Hokkaido \\ 060-0819, Japan
}

\begin{abstract}
In Drosophila elegans, partial sexual isolation has developed between the brown and black morphs, which are distributed allopatrically. The present study aims to understand how they discriminate between potential mates. Mating experiments show that the females of the two morphs differ in sexual signal(s) and the males discriminate using these differences. Body colouration is not used as a sexual cue in this species. Between the females of the two morphs, a large difference was observed in the percentages of 7-pentacosene and 9-pentacosene on the cuticle. Genetical analysis using recombinant inbred lines supported the possibility that the concentration of these pentacosenes plays a role in mate discrimination of these two morphs. However, males did not respond to killed females at all, suggesting that cuticular hydrocarbons of females are not the only cue for the induction of male courtship behaviour. It may be that unknown signals or substances are essential to induce male courtship and pentacosenes modulate the attractiveness of females, positively in the black morph and negatively in the brown morph. Drosophila elegans $\mathrm{F}_{1}$ offspring had intermediate characteristics in mate discrimination and hydrocarbon composition between the parental brown and black morph strains. The number of loci responsible for the differences in the concentration of pentacosenes and the male and female components in the mate recognition between these two morphs is suggested to be more than one.
\end{abstract}

Keywords: cuticular hydrocarbons, Drosophila, mate discrimination, sexual isolation.

\section{Introduction}

The differentiation of the mate recognition system is one of the major steps leading to speciation in animals, but little is understood about the evolution of mate recognition systems, because of its complexity. The mate recognition system can be divided into male and female components; individuals of one sex send signal(s) and individuals of the other sex respond to the signal(s) they received. Sexual signals are usually complicated and involve chemical, visual, behavioural and/or tactile stimuli. In Drosophila, courtship songs, cuticular hydrocarbons or morphological characteristics such as pigmentation or wing marks are known to act as sexual signals (Manning, 1959; Antony \& Jallon, 1982; Spieth \& Ringo, 1983). Among these signals, cuticular hydrocarbons have recently received much attention.

Like all insects examined so far, Drosophila flies carry a layer of long-chain hydrocarbons on the surface of their cuticle (Howard \& Blomquist, 1982). These com-

*Correspondence. E-mail: mtk@ees.hokudai.ac.jp pounds protect the insects from desiccation, and act in some species of Lepidoptera, Diptera and Coleoptera as contact pheromones (Howard \& Blomquist, 1982; Howard, 1993). In D. melanogaster, two female-specific cuticular hydrocarbons - 7,11-heptacosadiene and 7,11nonacosadiene - have been shown to induce male courtship behaviour, while a male-predominant cuticular hydrocarbon, 7-tricosene, inhibits the excitation of conspecific males (Antony \& Jallon, 1982; Jallon, 1984; Antony et al., 1985; Scott, 1994; Ferveur \& Sureau, 1996; Ferveur et al., 1997). In D. virilis, 11-pentacosene has been suggested to be the major sex pheromone (Oguma et al., 1992). In addition, the difference in female hydrocarbons has been indicated to contribute to sexual isolation between $D$. melanogaster and D. simulans or D. mauritiana (Savarit et al., 1999).

Knowledge of the genetic bases of the hydrocarbon differences contributing to sexual isolation is very important for understanding the speciation process. Usually, a number of genes are found to be responsible for hydrocarbon or pheromone differences between sibling or geographical strains of Drosophila (Coyne et al., 1994; 
Coyne, 1996; Ferveur \& Jallon, 1996; Coyne \& Charlesworth, 1997). However, Coyne et al. (1999) reported that a single gene is responsible for the difference in the level of 7,11-heptacosadiene between females of different geographical strains of $D$. melanogaster.

The present study aims to understand the evolution of the mate recognition system in D. elegans Bock and Wheeler. This species breeds mainly on Ipomoea (morning glory) flowers and its males hold mating territories on individual Ipomoea flowers (Kimura \& Hirai, 2001). Two morphs are known in this species: the black morph, which is distributed in the Ryukyu islands and Taiwan, and the brown morph, which occurs in southern China, the Philippines and Indonesia (Lemeunier et al., 1986; Hirai \& Kimura, 1997). We have shown previously that partial premating isolation has developed between these two morphs but postmating isolation between them is very weak (Hirai \& Kimura, 1997). In the present contribution, behavioural, chemical and genetic studies are undertaken to understand how they discriminate between mates.

\section{Materials and methods}

\section{Parental strains}

The experimental strain of the brown morph originated from about 20 females collected in Hong Kong, China (HK) and that of the black morph from about 30 females collected in Iriomote, Japan (IS). These strains were maintained in the laboratory for few years before the experiments.

Experimental flies were reared on cornmeal-malt medium at $23^{\circ} \mathrm{C}$ under continuous light conditions. Flies used in experiments were sexed without anaesthesia within $12 \mathrm{~h}$ after eclosion and maintained in glass vials $(50 \mathrm{~mL})$ containing food medium for 7 days.

\section{$F_{1}$ and $F_{2}$ hybrids}

The difference in body colouration between these morphs is the result of alleles on a single locus or closely linked loci on an autosome (Hirai \& Kimura, 1997): $F_{1}$ hybrids are intermediate in body colouration and $F_{2}$ individuals show three colour types, brown, intermediate and black.

\section{Recombinant inbred lines}

The genetical linkage between traits was investigated using recombinant inbred (RI) lines. Hybrids were produced by reciprocal crosses between the HK and IS strains and maintained independently by full-sib mating (mating between single brother and sister) from the $F_{2}$ generation. After 20 generations of full-sib mating, 24 recombinant inbred lines were obtained. In these inbred lines, $97.5 \%$ of loci are expected to be homozygous for one or other of the alleles of the parental strains (Falconer, 1960). If different traits under study are linked genetically, correlation would be observed between these traits among the recombinant inbred lines (Oliverio, 1979).

\section{Mate discrimination}

Mate discrimination of parental and $F_{1}$ flies was examined by courtship time and mating frequency in the male and female choice tests. In the choice-by-male test, a male and two females were introduced into a glass vial $(35 \mathrm{~mL})$ with an aspirator without anaesthesia. Duration of courtship exhibited to each female was measured until copulation had occurred, or for $45 \mathrm{~min}$ if copulation did not occur. The index for mate discrimination in courtship (DIC) was calculated by the following formula;

$\mathrm{DIC}=\left(\begin{array}{ll}A & B\end{array}\right) /(A+B)$,

where $A$ and $B$ are the number of replicates in which the males exhibit longer courtship to the females of strains $A$ and B, respectively. Values for DIC range from -1 to +1 and a value of zero indicates that males do not choose females. In this experiment, it was also observed with which female the male mated. The index for mate discrimination in mating (DIM) was calculated by the same formula as above; in this case, $A$ and $B$ are the number of replicates in which the males mated with the females of strains A and B, respectively.

DIC and DIM were also obtained in the choice-byfemale test in the same way.

It is possible to establish which sex discriminates between mates using these experiments. If females differ in attractiveness and males discriminate between them, males will exhibit longer courtship to attractive females and mate with them more often. If females discriminate between mates, males may show longer courtship to females that are reluctant to mate. If so, they would mate with females with which they exhibit shorter courtship.

In addition, the response of males to females killed by decapitation or low temperature $\left(-20^{\circ} \mathrm{C}\right)$ was examined to clarify the importance of cuticular hydrocarbons in the mate recognition.

\section{Cuticular hydrocarbons}

About 200 virgin flies were immersed in $n$-hexane for $2 \mathrm{~min}$ to extract cuticular hydrocarbons. The 
hydrocarbons were purified by silicic acid column chromatography and each component was identified by gas-liquid chromatography and mass spectrometry (GC-MS) using JMS-AX500 (JEOL Ltd., Tokyo, Japan) (Katagiri et al., 1985). A capillary column (DB1HT, $15 \mathrm{~m} \times 0.25 \mathrm{~mm}$ ) was run with $\mathrm{He}$ as carrier gas and heated from 130 to $230^{\circ} \mathrm{C}$ at $5^{\circ} \mathrm{C} \mathrm{min}{ }^{-1}$. For determining the position of double bonds, their dimethyl disulphide derivatives were subjected to GC-MS according to Carlson et al. (1989).

\section{Results}

\section{Mate discrimination}

In the choice-by-male test, males of the HK strain (the brown morph) exhibited longer courtship to females of the HK strain significantly more often than to those of the IS strain (the black morph), and also mated with HK females significantly more often (Table 1). Similarly, IS males exhibited a preference to IS females in courtship and mating. In the choice-by-female test, HK females received longer courtship from HK males significantly more often than from IS males, and mated with HK males significantly more often; also, IS females received longer courtship from IS males and mated with them significantly more often (Table 2 ). In these experiments, males mated significantly more often with females to which they exhibited longer courtship than with those to which they exhibited shorter courtship (Table 3), revealing that it is the male that discriminates between mates.

HK males showed longer courtship to HK females significantly more often than to $F_{1}$ females, and mated with HK females more often (Table 1). However, they did not discriminate between $F_{1}$ and IS females. IS males did not discriminate between $\mathrm{F}_{1}$, IS or $\mathrm{HK}$ females. In addition, $F_{1}$ males did not discriminate between IS and HK females (Table 1).

In order to examine whether body colour acts as a sexual cue or not, the choice-by-male test was made using $\mathrm{F}_{2}$ females with black and brown colouration. HK and IS males did not discriminate between brown and black $F_{2}$ females (Table 4 ), indicating that body colour is not used as a sexual cue.

Table 1 Results of choice-by-male tests with the black (IS) and brown morph (HK) strains of D. elegans and their $\mathrm{F}_{1}$ hybrids

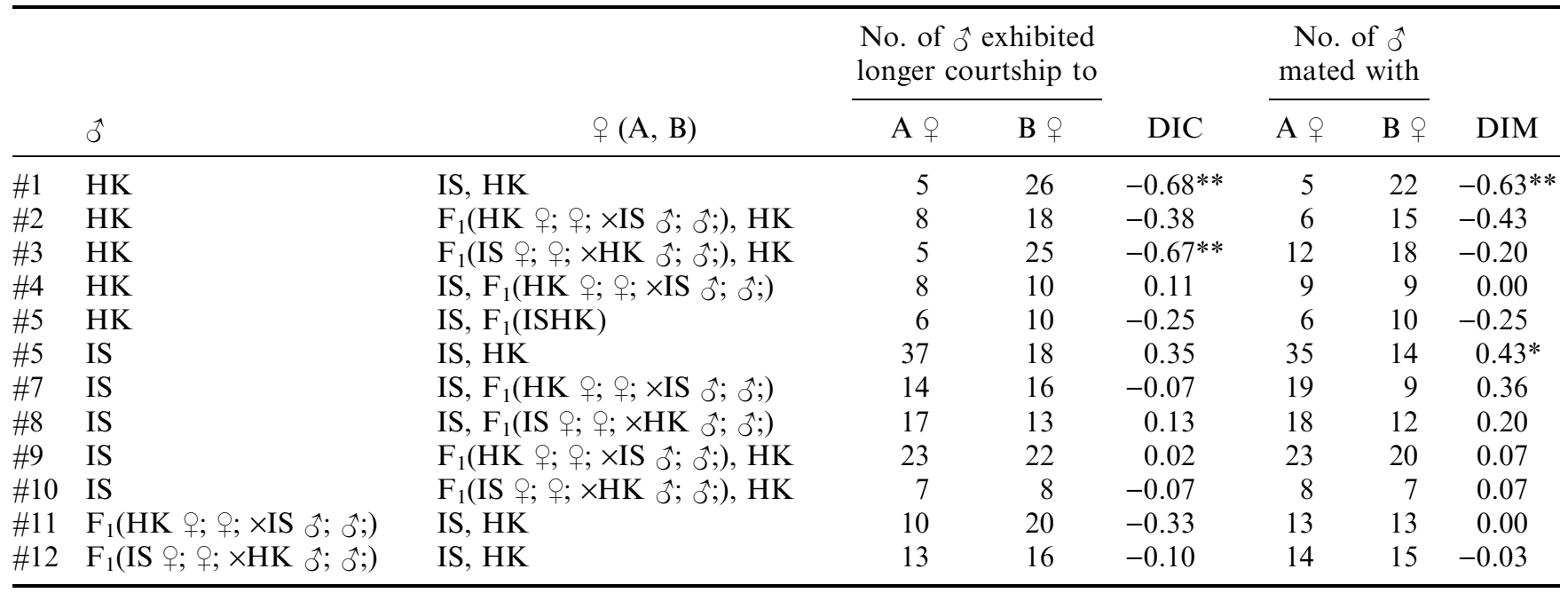

Significant deviation from random courtship or mating $\left(\chi^{2}\right.$-test after sequential Bonferroni correction, $\left.* P<0.05, * * P<0.01\right)$.

\begin{tabular}{|c|c|c|c|c|c|c|c|c|}
\hline & \multirow[b]{2}{*}{$\hat{o}(\mathrm{~A}, \mathrm{~B})$} & \multirow[b]{2}{*}{ ㅇ } & \multicolumn{2}{|c|}{$\begin{array}{l}\text { No. of } q \text { which } \\
\text { received longer } \\
\text { courtship from }\end{array}$} & \multirow[b]{2}{*}{$\mathrm{DIC}$} & \multicolumn{2}{|c|}{$\begin{array}{l}\text { No. of } q \\
\text { mating with }\end{array}$} & \multirow[b]{2}{*}{ DIM } \\
\hline & & & A $\widehat{\sigma}$ & $\mathrm{B}$ 。ै & & A $\hat{0}$ & $\mathrm{~B} \hat{0}$ & \\
\hline$\# 1$ & IS, HK & $\mathrm{HK}$ & 19 & 41 & $-0.37 * *$ & 17 & 36 & $-0.36 * *$ \\
\hline$\# 2$ & IS, HK & IS & 46 & 14 & $0.53 * *$ & 41 & 9 & $0.64 * *$ \\
\hline
\end{tabular}

Significant deviation from random courtship or mating $\left(\chi^{2}\right.$-test after sequential Bonferroni correction, $* * P<0.01)$.
Table 2 Results of choice-by-female tests with the black (IS) and brown morph (HK) strains of D. elegans 
Table 3 Number of replicates in which copulation occurred with females to which males exhibited longer (L) or shorter (S) courtship in the choice-by-male test in D. elegans, and number of replicates in which copulation occurred with males which exhibited longer (L) or shorter (S) courtship in the choice-by-female test. Experiment number, see Tables 1 and 2

\begin{tabular}{lll}
\hline Exp. No. & $\mathrm{L}$ & $\mathrm{S}$ \\
\hline Choice-by-male test & & \\
$\# 1$ & 24 & $3^{* *}$ \\
$\# 2$ & 15 & 6 \\
$\# 3$ & 21 & 9 \\
$\# 4$ & 15 & $3^{*}$ \\
$\# 5$ & 14 & $2^{*}$ \\
$\# 6$ & 43 & $6^{* *}$ \\
$\# 7$ & 20 & $8^{* *}$ \\
$\# 8$ & 29 & $1^{* *}$ \\
$\# 9$ & 35 & $8^{* *}$ \\
$\# 10$ & 14 & \\
Choice-by-female test & & \\
$\# 1$ & 50 & $3^{* *}$ \\
$\# 2$ & 46 & $4^{* *}$ \\
\hline
\end{tabular}

$\chi^{2}$ test after sequential Bonferroni correction $* P<0.05$, $* * P<0.01$.

\section{Response to killed females}

In order to clarify the importance of cuticular hydrocarbons in the mate recognition, the response of males to females that were killed by decapitation or freezing was examined. Males of both IS and HK strains did not show any response to killed females $(N=10$ for each treatment in each strain). This suggests that, even if hydrocarbons play an important role in the induction of male courtship, they are not the only cue.

\section{Cuticular hydrocarbons}

The GC profile of cuticular hydrocarbons are shown in Fig. 1. The analysis with GC/MS confirmed that the cuticular hydrocarbons were composed of a complex mixture of alkanes and alkenes containing from 21 to at least 29 carbon atoms (Table 5). Between the HK and IS females, a large difference was observed in the concentration of 9-pentacosene
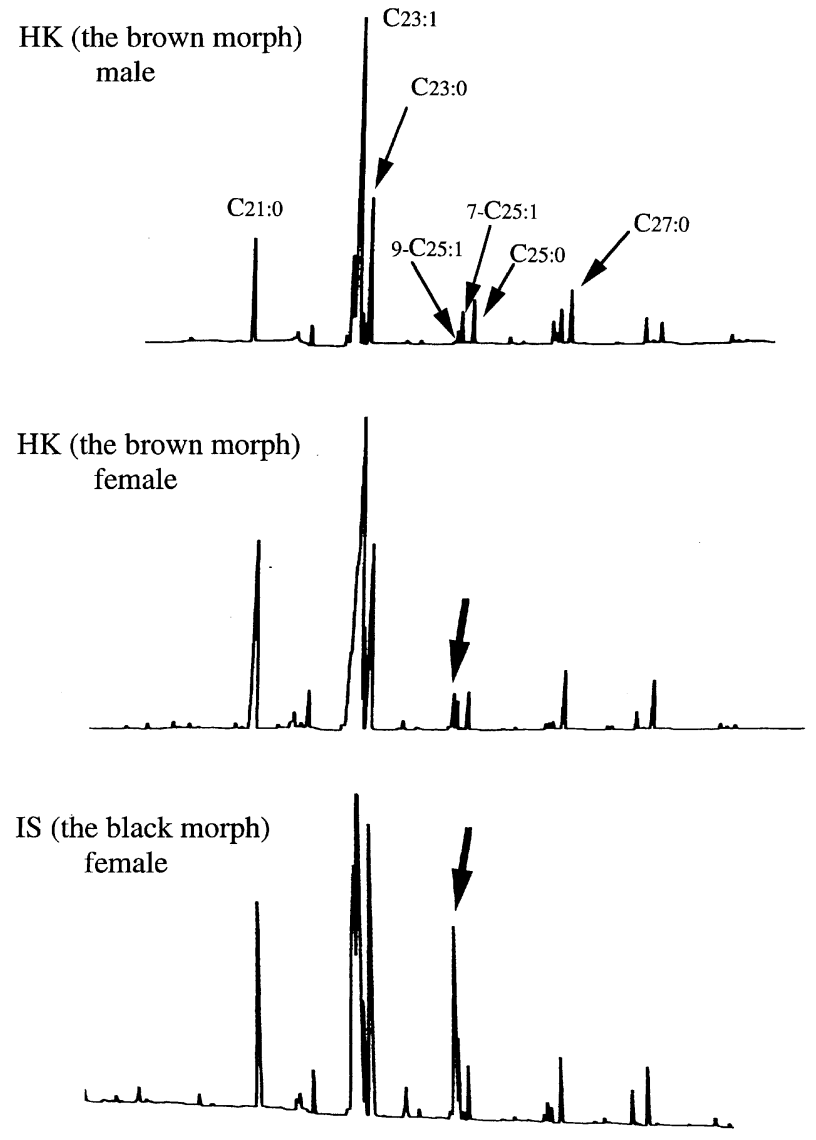

Fig. 1 Gas chromatograms of male and female Drosophila elegans (HK and IS). $\mathrm{C}_{21: 0}$ (heneicosane), $\mathrm{C}_{23: 1}$ (tricosene), $\mathrm{C}_{23: 0}$ (tricosane), 9- $\mathrm{C}_{25: 1}$ (9-pentacosene), 7- $\mathrm{C}_{25: 1}$ (7-pentacosene), $\mathrm{C}_{25: 0}$ (pentacosane) and $\mathrm{C}_{27: 0}$ (heptacosane). Arrows in lower two panels indicate $\mathrm{C}_{25: 1}$.

(9- $\left.\mathrm{C}_{25: 1}\right)$ and 7-pentacosene $\left(7-\mathrm{C}_{25: 1}\right)$; which are seven and three times higher in IS females than in HK females, respectively. On the other hand, the concentration of tricosenes $\left(\mathrm{C}_{23: 1}\right)$ was lower in the IS strain than in the HK strain, but the difference was only 1.15-fold because tricosenes were dominant (about $50 \%$ of total cuticular hydrocarbons). In both morphs, the concentration of $9-\mathrm{C}_{25: 1}$ was $1.5-3$ times higher than that of $7-\mathrm{C}_{25: 1}$. Female $\mathrm{F}_{1}$ offspring had intermediate concentrations of these hydrocarbons compared to IS and HK females.
Table 4 Results of choice-by-male tests on D. elegans using black and brown $\mathrm{F}_{2}$ females

\begin{tabular}{|c|c|c|c|c|c|c|}
\hline \multirow[b]{2}{*}{$\hat{0}$} & \multicolumn{2}{|c|}{$\begin{array}{l}\text { No. of ox exhibiting } \\
\text { longer courtship to }\end{array}$} & \multirow[b]{2}{*}{ DIC } & \multicolumn{2}{|c|}{ No. of ô mated with } & \multirow[b]{2}{*}{ DIM } \\
\hline & Black + & Brown $q$ & & Black ++ & Brown + & \\
\hline HK & 21 & 25 & -0.09 & 19 & 23 & -0.10 \\
\hline IS & 11 & 15 & -0.15 & 10 & 12 & -0.09 \\
\hline
\end{tabular}


Table 5 Cuticular hydrocarbon compositions (\%) in the experimental strains of D. elegans

\begin{tabular}{|c|c|c|c|c|c|c|c|c|c|c|c|c|}
\hline & \multicolumn{6}{|c|}{ Alkane } & \multicolumn{6}{|c|}{ Alkene } \\
\hline & $\mathrm{C}_{21}$ & $\mathrm{C}_{23}$ & $\mathrm{C}_{25}$ & $\mathrm{C}_{27}$ & $\mathrm{C}_{29}$ & total & $\mathrm{C}_{23: 1}$ & $9-C_{25: 1}$ & 7- $C_{25: 1}$ & $\mathrm{C}_{27: 1}$ & $\mathrm{C}_{29: 1}$ & total \\
\hline \multicolumn{13}{|c|}{ Female } \\
\hline HK & 17.78 & 14.70 & 1.70 & 3.13 & 2.53 & 39.84 & 55.97 & 1.62 & 1.09 & 0.72 & 0.76 & 60.15 \\
\hline IS & 12.30 & 14.33 & 2.09 & 2.83 & 2.59 & 34.14 & 48.25 & 11.04 & 3.35 & 1.70 & 1.50 & 65.86 \\
\hline $\mathrm{F}_{1}(\mathrm{~A})$ & 13.17 & 17.27 & 1.71 & 3.02 & 2.62 & 37.79 & 55.08 & 3.69 & 1.71 & 0.86 & 0.87 & 62.21 \\
\hline $\mathrm{F}_{1}(\mathrm{~B})$ & 14.15 & 16.57 & 1.83 & 3.19 & 2.01 & 37.75 & 56.19 & 2.72 & 1.53 & 0.80 & 1.01 & 62.25 \\
\hline \multicolumn{13}{|l|}{ Male } \\
\hline HK & 9.39 & 14.14 & 3.76 & 4.44 & 1.60 & 33.33 & 56.41 & 0.66 & 1.83 & 5.69 & 2.09 & 66.67 \\
\hline IS & 5.90 & 13.91 & 3.28 & 3.90 & 1.31 & 28.30 & 55.56 & 1.32 & 3.98 & 8.58 & 2.27 & 71.71 \\
\hline
\end{tabular}

$\mathrm{C}_{21}$ (heneicosane), $\mathrm{C}_{23}$ (tricosane), $\mathrm{C}_{25}$ (pentacosane), $\mathrm{C}_{27}$ (heptacosane), $\mathrm{C}_{29}$ (nonacosane), $\mathrm{C}_{23: 1}$ (tricosene),

9- $\mathrm{C}_{25: 1}$ (9-pentacosene), 7- $\mathrm{C}_{25: 1}$ (7-pentacpsene), $\mathrm{C}_{27: 1}$ (heptacosene), $\mathrm{C}_{29: 1}$ (nonacosene).

$F_{1}(A)$ was obtained from a cross between $\mathrm{HK}$ females and IS males, and $F_{1}(B)$ from a cross between IS females and HK males.

On the other hand, about twofold difference was observed in the concentrations of $\mathrm{C}_{21}, 7-\mathrm{C}_{25: 1}$ and $\mathrm{C}_{27: 1}$ between $\mathrm{HK}$ and IS males. Between the sexes, a difference was observed in the concentration of $\mathrm{C}_{27: 1}$.

\section{Genetic analysis}

Thus, hydrocarbon analysis detected a large difference in the concentration of pentacosenes between HK and IS females. In order to ascertain whether the difference in pentacosene concentration affects mate discrimination or not, the relationship between mate discrimination and pentacosene concentration was investigated with recombinant inbred (RI) lines.

Mate discrimination of RI flies was examined only by mating. The choice-by-male test was made for RI males using IS and HK females, and the choice-by-female test was made for RI females using IS and HK males. The discrimination index (DIM) was as follows,

$\mathrm{DIM}=\left(\begin{array}{ll}N_{\mathrm{IS}} & N_{\mathrm{HK}}\end{array}\right) /\left(N_{\mathrm{IS}}+N_{\mathrm{HK}}\right)$,

where $N_{\mathrm{HK}}$ and $N_{\text {IS }}$ are the numbers of HK and IS flies (respectively) with which RI flies mated. If RI males are the HK type, DIM would be-0.63, and if they are the IS type, it would be 0.43 (Table 1). If RI females are the HK type, DIM would be -0.36 , and if they are the IS type, it would be 0.64 (Table 2).

The distributions of male and female DIMs and female pentacosene concentration among RI lines are shown in Fig. 2. In this analysis, $7-\mathrm{C}_{25: 1}$ and $9-\mathrm{C}_{25: 1}$ were treated together, because the concentrations of these molecules were highly correlated among the RI lines $(r=0.86, P<0.001)$. If a single autsomal locus is responsible for the difference of these properties, the frequency of lines that show either the properties of the parental strains is expected to be 0.975 (the probability that an allele from one of the parental strains becomes homozygous is $0.975 / 2=0.4875$ ). However, the frequencies of lines that show either the properties of the parental strains were $0.1-0.2$, suggesting that more than one locus is responsible for the differences in DIMs and pentacosene concentration. In this study, it is difficult to estimate the number of genes precisely, because the number of RI lines obtained was only 24 .

DIM for the female was significantly correlated with the concentration of pentacosenes among RI lines (Fig. 3a), suggesting a relationship between the concentration of pentacosenes and mate discrimination by males. Male and female DIMs did not correlate with each other (Fig. 3b), indicating that the male and female components in their mate recognition system were controlled by different genetic systems.

\section{Discussion}

In D. elegans, partial sexual isolation has developed between the brown and black morphs (Hirai \& Kimura, 1997). The present mating experiments suggest that the females of the two morphs differ in sexual signal(s) and the males discriminate on the bases of these signal(s). It appears in this study that body colouration is not used as a sexual cue in this species. Between the females of the two morphs, a large difference was observed in the concentrations of 7-pentacosene $\left(7-\mathrm{C}_{25: 1}\right)$ and 9-pentacosene $\left(9-\mathrm{C}_{25: 1}\right)$. Genetic analysis using recombinant inbred lines suggests that the concentrations of 7- $\mathrm{C}_{25: 1}$ and $9-\mathrm{C}_{25: 1}$ play a role in mate discrimination between these two morphs.

However, males of this species do not show any response to killed females. This suggests that hydrocarbons are not the only cue for the induction of male courtship behaviour. Substances emitted through respiration, sounds or behaviours also play important 

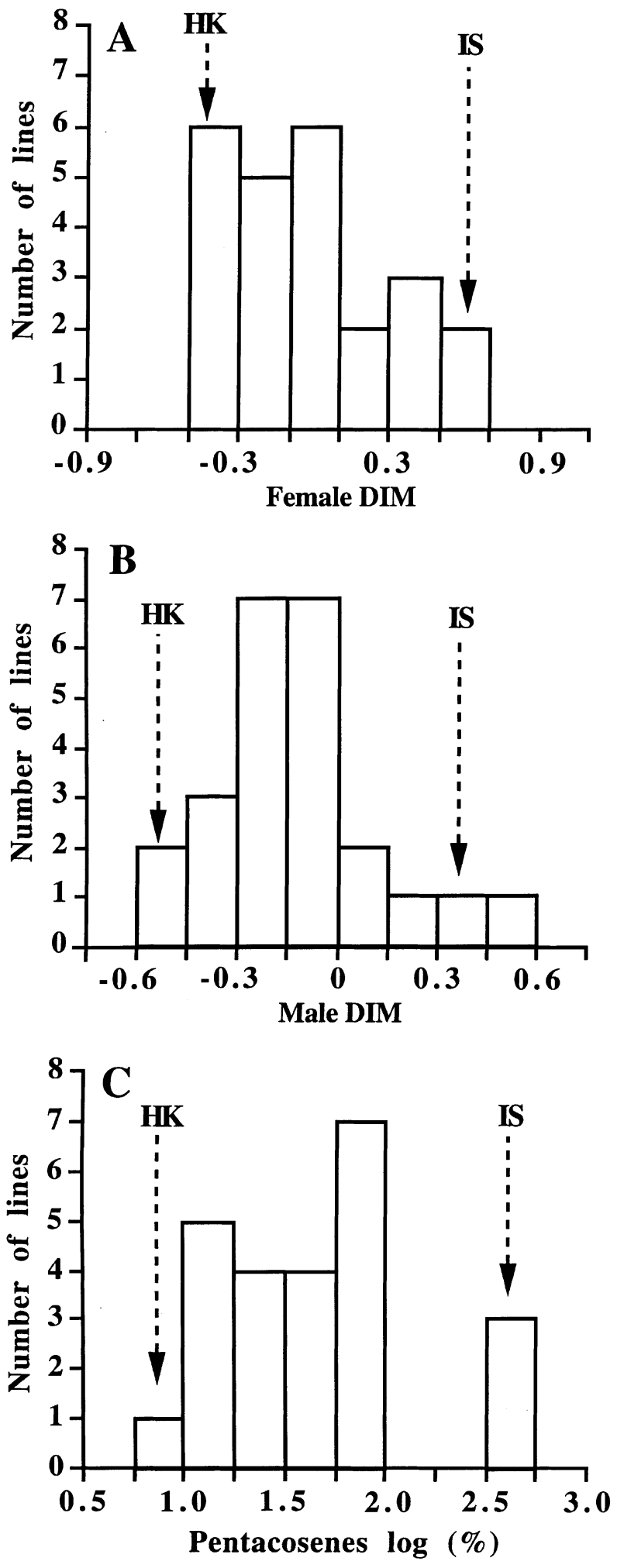

Fig. 2 Distributions of female DIM (A), male DIM (B) and female pentacosene concentration $(\mathrm{C})$ among recombinant inbred lines. Arrows (HK and IS) suggest the values when tested flies were the HK (the brown morph) and IS (the black morph) types, respectively.
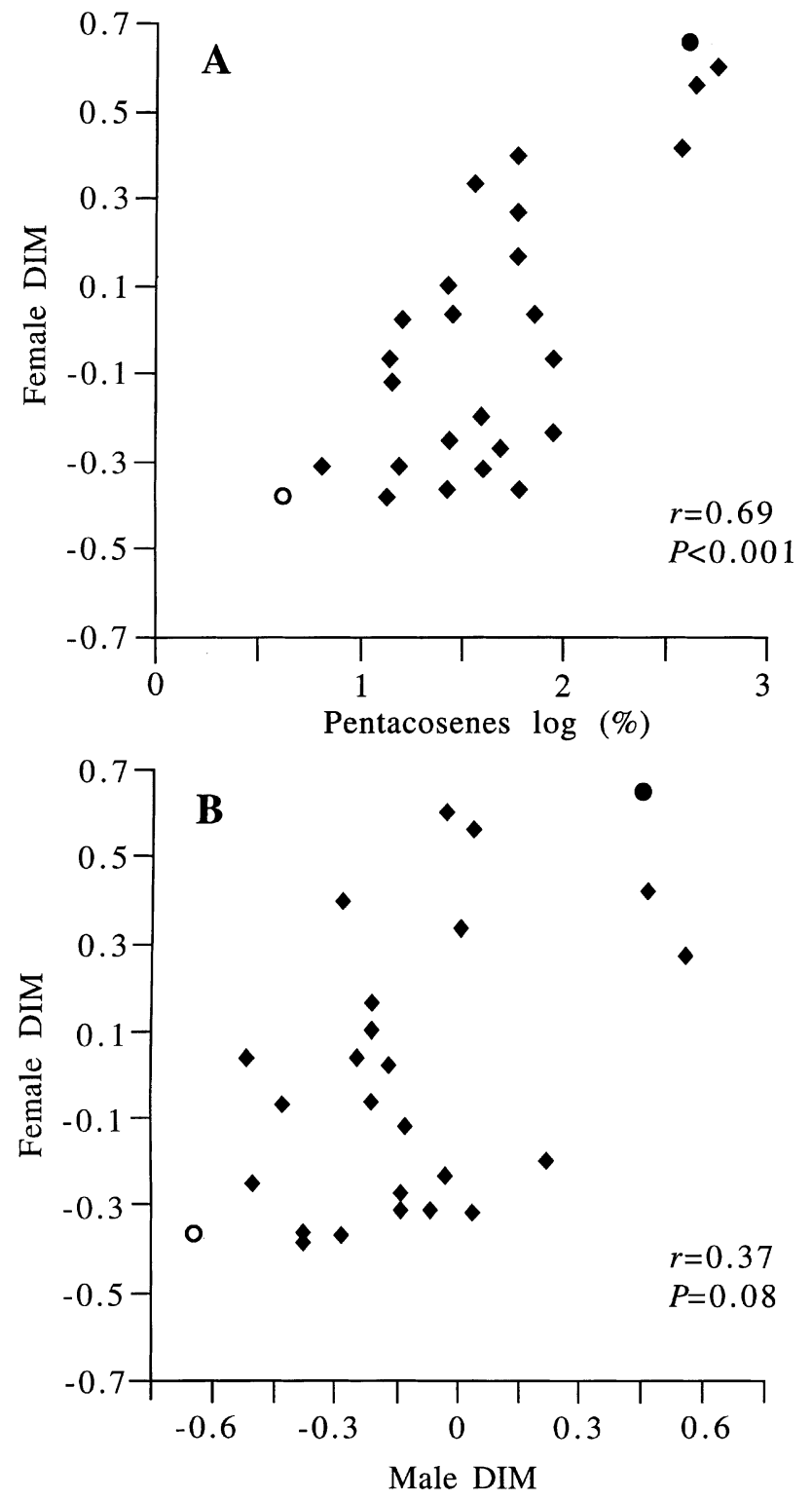

Fig. 3 Relationships between female DIM and female pentacosene concentration (A) and between male and female DIMs (B) among recombinant inbred lines. Open and closed circles indicate the values for the HK (the brown morph) and IS (the black morph) strains, respectively.

roles. In D. melanogaster and its siblings, Savarit et al. (1999) suggest that as-yet-undetermined substances act as essential copulation-stimulating pheromones and that the known cuticular pheromones modulate the action of essential pheromones positively or negatively; i.e. 7,11heptacosadiene acts positively for the $D$. melanogaster and $D$. sechellia males but negatively for the $D$. simulans and D. mauritiana males, while 7-tricosene shows the opposite action. In D. elegans, it may be that unknown signals or substances are essential to induce male

(C) The Genetics Society of Great Britain, Heredity, 87, 392-399. 
courtship and pentacosenes modulate the attractiveness of females; i.e. positively for IS males but negatively for HK males.

Previous studies on the genetic bases of hydrocarbon differences (Coyne et al., 1994; Coyne, 1996; Ferveur \& Jallon, 1996; Coyne \& Charlesworth, 1997) have reported that the differences in hydrocarbon profile between sibling species of the melanogaster species subgroup or between geographical strains of $D$. melanogaster are the result of evolutionary changes in at least four to six genes (although Coyne et al., 1999, reported that a single gene is responsible for the difference in the level of 7,11- $\mathrm{C}_{27: 2}$ between females of different geographical strains of $D$. melanogaster). The present genetic analysis suggests that the numbers of genes responsible for the difference in the concentration of pentacosenes and in the male and female components in the mate recognition system between these two morphs are more than one, in each case. The present analysis suggests also that the female and male properties in mate discrimination between these two morphs do not share a common genetic system. Thus, the number of loci responsible for sexual isolation between the black and brown morphs is at least four. In addition, sexual isolation between the morphs is incomplete, suggesting that the number of genes required for complete sexual isolation would not be small.

\section{Acknowledgements}

We thank Drs H. Okuyama and E. Fukushi for their help in the analysis of hydrocarbons. This work was partly supported in Grant-in-Aid from the Ministry of Education, Science, Sports and Culture of Japan (No. 10304062).

\section{References}

ANTONY, C. AND JALLON, J.-M. 1982. The chemical basis for sex recognition in Drosophila melanogaster. J. Insect Physiol., 28, 873-880.

ANTONY, C., DAVIS, T. L., CARlson, D. A., PECHINE, J.-M. AND JALLON, J.-M. 1985.Compared behavior responses of male Drosophila melanogaster (Canton S) to natural and synthetic aphrodisiacs. J. Chem. Ecol., 11, 1617-1629.

CARLSON, D. A., ROAN, C. R., YOST, A. AND HECOR, J. 1989. Dimetyl disulfide derivatives of long chain alkenes, alkadienes, and alkatrienes for gas chromatography/mass spectrometry. Analyt. Chem., 61, 1564-1571.

COYNE, J. A. 1996. Genetics of a difference in male cuticular hydrocarbons between two sibling species, Drosophila simulans and D. sechellia. Genetics, 143, 1689-1697.

COYNE, J. A. AND CHARLESWORTH, B. 1997. Genetics of a pheromonal difference affecting sexual isolation between Drosophila mauritiana and D. sechellia. Genetics, 145, 1015-1030.
COYNE, J. A., CRITTENDEN, A. P. AND MAH, K. 1994. Genetics of a pheromonal difference contributing to reproductive isolation in Drosophila. Science, 265, 1461-1464.

COYNE, J. A., THOMAs, C. W. AND JALlon, J.-M. 1999. A gene responsible for a cuticular hydrocarbon polymorphism in Drosophila melanogaster. Genet. Res., 73, 189-203.

FALCONER, D. S. 1960. Introduction to Quantitative Genetics. Oliver AND Boyd, Edinburgh.

FERVEUR, J.-F. AND JALLON, J.-M. 1996. Genetic control of male cuticular hydrocarbons in Drosophila melanogaster. Genet. Res., 67, 211-218.

FERVEUR, J.-F. AND SUREAU, G. 1996. Simultaneous influence on male courtship of stimulatory and inhibitory pheromones produced by live sex-mosaic Drosophila melanogaster. Proc. R. Soc. B, 263, 967-973.

FERVEUR, J.-F., SAVARIT, F., O'KANE, C. J., SUREAU, G., GREENSPAN, R. J. AND JALlON, J.-M. 1997. Genetic feminization of pheromones and its behavioral consequences in Drosophila males. Science, 276, 1555-1558.

HIRAI, Y. AND KIMURA, M. T. 1997. Incipient reproductive isolation between two morphs of Drosophila elegans (Diptera: Drosophilidae). Biol. J. Linn. Soc., 61, 501-513.

HOWARD, R. W. 1993. Cuticular hydrocarbons and chemical communication. In: Stanley-Samuelson, D. W. and Nelson, D. R. (eds) Insect Lipids: Chemistry, Biochemistry and Biology, pp. 179-226. University of Nebraska Press, Lincoln, NB.

HOWARD, R. W. AND BlomQUist, G. J. 1982. Chemical ecology and biochemistry of insect hydrocarbons. Ann. Rev. Ent., 27, $149-172$.

JALLON, J.-M. 1984. A few chemical words exchanged by Drosophila during courtship and mating. Behav. Genet., 14, 441-478.

KATAGIRI, C., KIMURA, J. AND MURASE, N. 1985. Structural studies of lipophorin in insect blood by differential scanning calorimetry and ${ }^{13} \mathrm{C}$ nuclear magnetic relaxation measurements. J. Biol. Chem., 260, 13490-13495.

KIMURA, M. T. AND HIRAI, Y. 2000. Daily activity and territoriality of Drosophila elegans in Sukarami, West Sumatra, Indonesia. Tropics, 10, 489-495.

LEMEUNIER, F., DAVID, J. R., TSACAS, L. AND ASHBURNER, M. 1986. The melanogaster species group. In: Ashburner, M. Carson, H. L. and Thompson, J. N., jr (eds) The Genetics and Biology of Drosophila, Vol. 3e, pp. 147-256. Academic Press, London.

MANNING, A. 1959. The sexual isolation between Drosophila melanogaster and Drosophila simulans. Anim. Behav., 7, $60-65$.

OGUMA, Y., NEMOTO, T. AND KUWAHARA, Y. 1992. (Z)-11Pentacosene is the major sex pheromone component in Drosophila virilis (Diptera). Chemoecology, 3, 60-64.

OLIVERIO, A. 1979. Use of recombinant inbred lines. In: Thompson, J. N., jr AND Thoday, J. M. (eds) Quantitative Genetic Variation, pp. 197-218. Academic Press, New York. SAVARIT, F., SUREAU, G., COBB, M. AND FERVEUR, J.-F. 1999. Genetic elimination of known pheromones reveals the fundamental chemical bases of mating and isolation in Drosophila. Proc. Natl. Acad. Sci. U.S.A., 96, 9015-9020. 
SCOTT, D. 1994. Genetic variation for female mate discrimination in Drosophila melanogaster. Evolution, 48(1), 112-121. SPIETH, H. T. AND RINGO, J. M. 1983. Mating behavior and sexual isolation in Drosophila. In: Ashburner, M. Carson,
H. L. and Thompson, J. N., jr (eds) The Genetics and Biology of Drosophila, Vol. 3c, pp. 224-284. Academic Press, London. 